\title{
Mechanical and fluid-dynamic behaviour of debris and hyper-concentrated flows: overview and challenges
}

\author{
D. De Wrachien ${ }^{1}, \mathrm{~S}$. Mambretti $^{2} \&$ C. Deangeli ${ }^{3}$ \\ ${ }^{1}$ Department of Agricultural Engineering, State University of Milan, Italy \\ ${ }^{2}$ DIIAR, Politecnico di Milano, Italy \\ ${ }^{3}$ DITAG, Politecnico di Torino, Italy
}

\begin{abstract}
Debris and hyper-concentrated flows are among the most destructive of all water-related disasters. They mainly affect mountain areas in a wide range of morphoclimatic environments and in recent years have attracted more and more attention from the scientific and professional communities and concern from public awareness, due to the increasing frequency with which they occur and the death toll they claim. In this context, achieving a set of debris and hyper-concentrated flow constitutive equations is a task that has been given particular attention by scientists during the second half of the last century.

In relation to these issues, this paper reviews the most updated and effective geotechnical and fluid-dynamic procedures nowadays available, suitable to predict the triggering and mobilising processes of these phenomena, and proposes a mathematical model that is able to assess the depth of the wave and the velocities of the liquid and solid phases of both non-stratified (mature) and stratified (immature) flows following flash-floods and dam-break events in one and two dimensional cases.

Different experimental cases of dam-break situations in a square section channel were considered for the purpose of comparing results.

These tools will allow, on one hand, to better focus on what to observe in the field and, on the other hand, to improve both mitigation measures and hazard mapping procedures.
\end{abstract}

Keywords: debris flow, rheological behaviour of the mixture, slope failure, numerical models, laboratory and field tests. 


\section{Introduction}

Debris and hyper-concentrated flows are among the most destructive of all water-related disasters. They mainly affect mountain areas in a wide range of morphoclimatic environments and in recent years have attracted more and more attention from the scientific and professional communities and concern from public awareness due to the increasing frequency with which they occur and the death toll they claim. These phenomena do not allow a sufficient early warning, as they are characterised by a very short time-scale and, therefore, defence measures should be provided, especially when they are associated with flash floods or dam failures. To this end, the identification of effective procedures aimed at evaluating the probability of these extreme events and the triggering and mobilising mechanism has become an essential component of the water and land use planning processes. This concept leads to a new integrated risk management approach, which comprises administrative decisions, organisation, operational skill and the ability to implement suitable policies. The broadness of the question requires approaches from various perspectives.

To this end, the dynamic behaviour of these hyper-concentrated water sediment mixtures and the constitutive laws that govern them plays a role of paramount importance.

Debris flow modelling requires a rheological pattern (or constitutive equation) that provides an adequate description of these flows.

One of the main difficulties met by the approaches available is linked to their validation either in the field or in a laboratory environment. Greater research needs to be directed towards a thorough investigation of the above mentioned issues.

Such knowledge is essential in order to assess the potential frequency of these natural hazards and the related prevention and mitigation measures.

With reference to these issues, this paper aims to provide the state-of-the-art of debris flow rheology, modelling and laboratory and field investigation, along with a glance to the direction that debris flow in-depth studies are likely to follow in future.

\section{Debris flow model development}

A thorough understanding of the mechanism triggering and mobilising debris flow phenomena plays a role of paramount importance for designing suitable prevention and mitigation measures. Achieving a set of debris flow constitutive equations is a task which has been given particular attention by the scientific community (Julien and O'Brien [33]; Chen [9]; Takahashi [35]). To properly tackle this problem relevant theoretical and experimental studies have been carried out during the second half of the last century.

Research work on theoretical studies has traditionally specialised in different mathematical models. They can be roughly categorized on the basis of three characteristics: the presence of bed evolution equation, the number of phases and the rheological model applied to the flowing mixture (Ghilardi et al. [24]). 
Most models are based on the conservation of mass and momentum of the flow, but only a few of them take into account erosion/deposition processes affecting the temporal evolution of the channel bed.

Debris flows are mixtures of water and clastic material with high coarse particle contents, in which collisions between particles and dispersive stresses are the dominant mechanisms in energy dissipation.

The rheological property of a debris flow depends on a variety of factors, such as suspended solid concentration, cohesive property, particle size distribution, particle shape, grain friction and pore pressure.

Various researchers have developed models of debris flow rheology. These models can be classified as: Newtonian models (Johnson [32]), linear and non linear viscoplastic models (O’Brien et al. [41]), dilatant fluid models (Bagnold [4]), dispersive or turbulent stress models (Arai and Takahashi [2]), biviscous modified Bingham model (Dent and Lang [15]), and frictional models (Norem et al. [40]). Among these, linear (Bingham) or non-linear (Herschel-Bulkey) viscoplastic models are widely used to describe the rheology of laminar debris/mud flows (Jan, 1997).

Because a debris flow, essentially, constitutes a multiphase system, any attempt at modelling this phenomenon that assumes, as a simplified hypothesis, homogeneous mass and constant density, conceals the interactions between the phases and prevents the possibility of investigating further mechanisms such as the effect of sediment separation (grading).

Modelling the fluid as a two-phase mixture overcomes most of the limitations mentioned above and allows for a wider choice of rheological models such as: Bagnold's dilatant fluid hypothesis (Takahashi and Nakagawa [56]), Chézy type equation with constant value of the friction coefficient (Hirano et al. [27]), models with cohesive yield stress (Honda and Egashira [28]) and the generalized viscoplastic fluid Chen's model (Chen and Ling [10]).

Notwithstanding all these efforts, some phenomenological aspects of debris flow have not been understood yet, and something new has to be added to the description of the process to reach a better assessment of the events. In this contest, the mechanism of dam-break wave should be further investigated. So far, this aspect has been analysed by means of the single-phase propagation theory for clear water, introducing in the De Saint Venant (SV) equations a dissipation term to consider fluid rheology (Coussot [12]; Fread and Jin [23]).

Many other models, the so-called quasi-two-phase-models, use SV equations together with erosion/deposition and mass conservation equations for the solid phase, and take into account mixture of varying concentrations. All these models feature monotonic velocity profiles that, generally, do not agree with experimental and field data.

\subsection{Rheology}

The rheological property of debris and hyper-concentrated flows depends on a variety of factors, such as the suspended solid concentration, cohesive property, size distribution, particle shape, grain friction, and pore pressure. So, modelling 
these flows requires a rheological model (or constitutive equation) for sedimentwater mixtures.

A general model which can realistically describe the rheological properties of debris flow should possess three main features (Chen [9]). The model should:

- describe the dilatancy of sediment-water mixtures;

- take into account the so-called soil yield criterion, as proposed by Mohr-Coulomb;

- $\quad$ assess the role of intergranular or interstitial fluid.

The earliest of such rheological models was empirically formulated by Bagnold [4].

On the whole, a rheological model of debris and hyper-concentrated flows should involve the interaction of several physical processes. The non-Newtonian behaviour of the fluid matrix is ruled, in part, by the cohesion between fine sediment particles. This cohesion contributes to the yield stress, which must be exceeded by an applied stress in order to initiate fluid motion.

In view of theoretical soundness behind the development of different nonNewtonian fluid models, Bailard [5] and Hanes [25] have questioned the validity of Bagnold's empirical relations. Limitations in Bagnold's model may be attributed to the ambiguity in the definition of some rheological characteristics as the grain stresses.

To overcome these problems, Chen [9] developed a new generalised viscoplastic fluid (GVF) model, based on two major rheological properties (i.e. the normal stress effect and soil yield criterion) for general use in debris flow modelling.

The analysis Chen conducted on the various flow regime of a granular mixture identified three regimes: a quasi-static one, which is a condition of incipient movement with plastic behaviour, a microviscous one at low shear rates, in which viscosity determines the mixture behaviour, and finally a granular inertial state, typical of rapid flowing granular mixtures, dominated by intergranular interactions.

All the models previously reviewed feature monotonic velocity profiles that, generally, do not agree with experimental and field data. In many tests (Takahashi [53]) " $S$ " reversed shaped trends have been observed, where the maximum shear rate is not achieved near the bed, but rather between the bed and the free surface. The main discrepancy is derived from the assumption of a debris flow as a uniform mixture. In fact, the solid concentration distribution is usually non-uniform due to the action of gravity, so that the lower layer could, consequently, have a higher concentration than the upper layer. Higher concentration means higher cohesion, friction and viscosity in the flow.

Wan [58] proposed a multilayered model known as the laminated layers model that features a stratified debris flow into three regions from the bed to the surface: a bed layer, in which an additional shear stress is dominant in momentum exchange; an inertial layer, where the dispersive stress of the grains is dominant; and an upper viscoplastic layer, which can be represented by the Bingham's model. 
The one-layer models are unable to adequately feature the entire thickness of the flow and, therefore, it has recently become common to use multi-layers models that combine two or more constitutive relationships in order to analyse adequately these phenomena. The coefficients of the rheological models have wide ranges of variation and, therefore, in evaluating them considerable errors are committed. On the other hand, some empirical equations of velocity are necessary in any debris flow disaster-forecasting measure, although the hydraulics of debris-flow is not theoretically comparable to that of a traditional water flow.

\subsection{Triggering and mobilising processes}

Debris flow resulting from flash flood or a sudden collapse of a dam (dam-break) are often characterised by the formation of shock waves caused by many factors such as valley contractions, irregular bed slope and non-zero tailwater depth. It is commonly accepted that a mathematical description of these phenomena can be accomplished by means of 1D SV equations (Bellos and Sakkas [6]).

During the last Century, much effort has been devoted to the numerical solution of the SV equations, mainly driven by the need for accurate and efficient solvers for the discontinuities in dam-break problems.

A rather simple form of the dam failure problem in a dry channel was first solved by Ritter [46] who used the SV equations in the characteristic form, under the hypothesis of instantaneous failure in a horizontal rectangular channel without bed resistance. Later on, Stoker [50], on the basis of the work of Courant and Friedrichs [11], extended the Ritter solution to the case of wet downstream channel. Dressler [19] used a perturbation procedure to obtain a first-order correction for resistance effects to represent submerging waves in a roughing bed.

Lax and Wendroff [35] pioneered the use of numerical methods to calculate the hyperbolic conservation laws. McCormack [39] introduced a simpler version of the Lax-Wendroff scheme, which has been widely used in aerodynamics problems. Van Leer [57] extended the Godunov scheme to second-order accuracy by following the Monotonic Upstream Schemes for Conservation Laws (MUSCL) approach. Chen [7] applied the method of characteristics, including bed resistance effects, to solve dam-break problems for reservoir of finite length.

Sakkas and Strelkoff [47] provided the extension of the method of the characteristics to a power-law cross section and applied this method to a dam break on a dry right channel in the case of rectangular and parabolic cross section shapes. Strelkoff and Falvey [52] presented a critical review of numerical methods of characteristics of power-law cross sections.

Hunt [29] proposed a kinematic wave approximation for dam failure in a dry sloping channel.

Total Variation Diminishing (TVD) and Essentially Non Oscillation (ENO) schemes were introduced by Harten [26] for efficiently solving 1D gas dynamic problems. Their main property is that they are second order accurate and oscillation free across discontinuities. 
Recently, several 1D and 2D models using approximate Riemann solvers have been reported in the literature. Such models have been found very successful in solving open channel flow and dam-break problems.

In the past ten years, further numerical methods to solve flood routing and dam-break problems, have been developed that include the use of finite elements or discrete/distinct element methods (Asmar et al. [3]).

Finite Element Methods (FEMs) have certain advantages over finite different methods, mainly in relation to the flexibility of the grid network that can be employed, especially in 2D flow problems.

Mambretti et al. [38] and De Wrachien and Mambretti [17, 18] used an improved TVD-Mc Cormack-Jameson scheme to predict the dynamics of both mature (non-stratified) and immature debris flow in different dam break conditions.

\section{Laboratory and field studies}

To validate both the rheological and dynamic models, herewith described, comparisons need to be made between their predictions and results of laboratory and field tests. Agreements between the computational and experimental results are essential since they allow the assessment of the models' performance and suggest feasible development of the research.

The experimental point of view in debris flow research, however, encounters considerable problems that are yet to be fully overcome, connected largely to the accuracy of measuring techniques and flow simulation in experimental tests. Lastly, field studies are probably the most difficult and costly study approach of debris flow; the difficulties encountered are connected to their considerable complexity and the difficulty of direct observation. The exceptional and infrequent conditions in which debris flows occur do not generally permit a sufficient number of observations for the same type of field reality to deduce the specific behavioural laws for that area. Reference to different territorial situations also highlights another problem: that of the homogeneity of data, given the substantial territorial peculiarity in which the phenomena occur. Besides, field data are essential in determining the quality of any mathematical model, as they are especially important for estimating velocity, discharge, concentration, yield stress, viscosity and grain-size.

This need requires the use of laboratory experimentation when the previous problems cannot be overcome, and in certain cases it is the only possible path to follow.

Within this ground, many experiments have been carried out, ranging from solid transport (little amount of particles in a large environment of clear water) to dry granular flow, where water is not present.

An empirical picture of debris flow physics can be drawn from a combination of real-time field observations (Okuda et al. [42]); detailed measurements during controlled field and laboratory experiments (Takahashi [54]), and analyses of debris flow paths and deposits (Fink et al. [21]). 
Few reliable techniques exist to measure properties of flowing debris. Grossly invasive procedures such as plunging buckets or sensors into the flows conspicuously change the dynamics of the debris, while their behaviour has discouraged attempts to use non-invasive techniques such as ultrasonic, $\mathrm{X}$ ray, and others (Lee et al. [36]; Abbott et al. [1]).

With regard to the rheological properties, many experiments (Chen [8]) have shown that the Herschel-Bulkley equations fit quite well laboratory data. One of the criticisms that may be moved to these tests is related to the scale effect.

Successful models of debris flows must describe the mechanics of mobilization as well as the subsequent flow and deposition processes. Mobilization requires failure of the mass, a quantity of water to saturate the solid phase, such a change of energy, from gravitational to kinetic, to modify the motion pattern from sliding along a failure surface to a more widespread solidliquid mixture that can be assessed as flow.

On the whole, laboratory and field data are essential in determining the quality of any mathematical model, as it is especially important for estimating velocity, discharge, concentration, yield stress, viscosity and grain-size (Lorenzini and Mazza [37]). However, the achievement of good agreement between theoretical and experimental results does not justify indiscriminate extrapolation for the various territorial situations, which have very different boundary conditions from standard laboratory conditions. Assuming that the scientific research path cannot exclude an accurate observation and description of the phenomenon in question, without which the analysis of physical processes, that generate it, would become extremely artificial and uncertain, it is hoped that any attempt at improving the interpretation of the phenomenon involves critical comparison between the theoretical, experimental, and field approaches, as well as extensive osmosis process between the same approaches.

\section{Debris flows generated by slope failures}

Debris flows can be the result of some form of landslides. In particular sliding phenomena in granular soils can turn into flow like movements.

The main difference between slides and flow like landslides concerns the mechanisms of movement. While a slide advances on the slip surface as a rigid block or with a small internal deformation, a flow spreads downslope as a viscous fluid, adapting itself to any morphological change encountered along its path.

In some conditions shear failure (sliding) can be affected by a rapid increase of positive pore pressures in excess to the hydrostatic values. The raise of excess pore pressures decreases the shear resistance of the soil inducing an acceleration of the movement: under these conditions the process can originate a debris flow.

The triggering of positive excess pore pressure in loose granular materials can occur if the soil is saturated and the mechanism of slope deformation is characterized by fast volumetric compression. 
The occurrence of flow like movements is dependent on the un-drained behaviour of the soil, which refers to the condition of a saturated soil deforming at constant volume.

The knowledge of the un-drained response of granular soils is of critical importance in assessing their susceptibility to liquefaction. The term liquefaction is frequently used to indicate all phenomena involving excessive deformation in saturated cohesionless soils and is not limited to the development of $100 \%$ excess pore pressure. Liquefaction can be triggered by either static or cyclic loading. Liquefaction due to static loading is associated with granular soils deforming in a strain softening (or limited strain softening) manner that results in limited or unlimited unidirectional flow deformation (Sivathayalan and Vaid [48]).

A fundamental understanding of the un-drained response of granular soils has been derived from controlled laboratory studies. Un-drained triaxial compression tests on sand specimens mostly reconstituted by moist tamping have formed the basis for the steady state concepts (Poulos [44]).

Susceptibility of soil to liquefaction mainly depends on grain size and porosity, but also on stress conditions (Picarelli et al. [43]).

Ishihara et al. [30] presented the results of a series of laboratory tests, using triaxial apparatus, on saturated samples of Toyoura sand consolidated anisotropically. They found that with an increasing degree of anisotropy at the time of consolidation the sample becomes more contractive and susceptible to triggering flow failure. They found that the major effective principal stress at the time of anisotropic consolidation is a parameter controlling dilative or contractive behaviour of the sand. As a result the most appropriate way to normalise the residual strength of anisotropically consolidated sand is by the use of major principal stress at consolidation. The quasi steady state strength is then a function of void ratio and the major effective stress at consolidation.

Other contributions devoted to the assessment of the potential for liquefaction of a soil are based on the concept of region of instability (Sladen et al. [49]). Soil instability is a phenomenon that resembles liquefaction in that there is a sudden decrease in the soil strength under un-drained conditions. This loss of strength is related to the development of large pore pressures reducing effective stresses in the soil. Lade [34] showed that there exists a region of instability inside the failure surface. The loss of strength occurs in un-drained condition as a consequence of disturbances small but fast enough to prevent water drainage.

Conventional slope stability analysis methods (limit equilibrium methods) are widely used to investigate landslide problems and to determine the state of stress in slopes. This type of analysis has been used by Lade [34] for the determination of the state of stress in finite slope made of loose sand in order to investigate the region of instability by varying the slope height.

Deangeli [13] presented a study devoted to the assessment of the potential for liquefaction in all zones of finite slopes from the in situ state of stress. For these purposes numerical models reproducing different slopes have been set up by using a finite difference code (FLAC manuals, 2001). The state of stress in slopes has been evaluated in both elastic and elastic-plastic field. By relating this 
state of stress to the parameters stated by Ishihara et al. [30] to describe the potential for liquefaction a chart of susceptibility of debris flow in soil slopes has been set up. The chart reports curves that establish the limit condition on the basis of critical combinations of void ratio, slope angle and slope height.

In this context some authors define a slope safety factor against liquefaction. For instance Poulos et al. [45] proposed the ratio between the residual strength of the soil $S_{u s}$ (the minimum resistance in un-drained conditions for a contractive soil with respect to the in situ void ratio) and the shear stress required for static equilibrium along the potential sliding surface. Ishihara et al. [30] defined the safety factor as the ratio between the residual strength of the soil (which is dependent on the major effective principal stress at the time of anisotropic consolidation) and the maximum shear stress along the potential sliding surface.

Deangeli [13] reported the safety factor against liquefaction along different surfaces passing through a slope and assessed the volume of soil potentially involved in debris flow.

The analysis of the propagation of debris flows generated by slope failures can be performed by taking into account the initial value of excess pore pressure (after slope failure) and its dissipation along the path.

Significant results have been obtained by instrumented laboratory flume experiments. In these experiments the role of pore pressure in the flow failure phase, i.e. the transition from sliding to flow was investigated (Eckersley [20]).

Deangeli [14] set up series of flume experiments to analyze the behaviour of water sand mixture flows, as a consequence of slope failures induced by water table raising and rainfall. The flows initially accelerated but at a certain stage of the process, unsteady deposition of the sand occurred, preceded by the transformation of the movement from flow to sliding. The phenomenon of deposition of the soil along the flume occurred at inclination greater than in the case of Spence and Guymer [51] experiments.

On the basis of the reported results, it is evident the need of further experimental works investigating the dependence of debris flow behaviour by the triggering mechanisms and the role and generation of pore pressure during the propagation phase.

\section{Concluding remarks}

Debris and hyper-concentrated flow result from the interaction of hydrological processes with geological processes and are triggered when soils get saturated and the stability of the slope is no longer maintained. These flows are among the most destructive of all water-related disasters. In this context, the recognised need to improve knowledge on the mechanics of these solid-liquid flows, highlighted by a critical analysis of the current international state-of-the-art, represent the seeding of the present work.

Although the main aspects that rule the mechanics of these phenomena seem to be understood, it has to be underlined the relative scarcity of experimental (laboratory and field) data, the only ones that allow effective check of the models 
nowadays available in different flow conditions and the estimation of the rheological parameters they contain.

Greater research needs to be directed towards understanding the nature and the behaviour of these flows. Such knowledge is essential in order to estimate the potential frequency of these natural hazards and design suitable prevention and remediation measures.

The ideal sequence that should be pursued in the approach to the difficult task of the management and mitigation of hyper-concentrated and debris flow can be obtained as follows (De Wrachien [16]):

- first, a systematic collection of field data should be carried out in order to provide a large base of reliable data that could allow a better knowledge of the existing risk trends and a deeper understanding of the mechanics of the phenomena, along with their general behaviour and effects;

- secondly, effective mathematical models, which strongly depend on data and measurements collected and performed in the field for their calibration and design, should be constantly developed, updated when needed, tested and applied;

- hazard mapping techniques and identification of possible scenarios, which need reliable models to be effective and sound, should then be set up;

- $\quad$ on the basis of the knowledge achieved in the previous steps, the best mitigation solutions should be identified, designed and built up;

- finally a program of systematic observations on the sites, where risk has been mitigated, should be planned and carried out to detect any shortcoming and test the efficiency of the investigations.

Each of the above studies and investigations needs improvements and depends, to achieve them, on improvements in other fields. Improving measurement and documentation procedures would provide a better knowledge and ideas for new and more advanced models. The application of existing models based on the data collected in the field and the development of reliable new ones would allow, on one hand, to better focus what to observe in field and, on the other hand, improve mitigation measures and procedures. The field application of these latter would then identify new parameters to be measured and introduced in the models.

From all these activities would emerge the best direction to be followed in future in-depth studies and investigations of debris flows.

\section{References}

[1] Abbott J., Mondy L.A., Graham A.L., Brenner H. Techniques for analyzing the behaviour of concentrated suspensions, in Particulate Two-Phase Flow, edited by M. C. Roco, pp. 3-32, Butterworth-Heinemann. Newton, Mass., 1993. 
[2] Arai M., Takahashi T., The Karman constant of the flow laden with high sediment in Proc. of the 3rd International Symposium on River Sedimentation University of Mississippi, 1986, pp. 824-833

[3] Asmar B.N., Lanston P.A., Ergenzinger Z., The potential of the discrete method to simulate debris flow in Proceeding of the First International Conference on Debris Flow Hazard Mitigation: Mechanics, Prediction and Assessment, Eds. Chen, New York, 1997

[4] Bagnold R.A., Experiments on a gravity-free dispersion of large solid spheres in a Newtonian fluid under shear in Proceedings of the Royal Society of London, Series A, 225, 1954, pp. $49-63$

[5] Bailard J.A. An experimental study of granular-fluid flow Thesis presented to University of California at San Diego, Calif., 1978

[6] Bellos V., Sakkas J.G., 1D dam - break flood propagation on dry bed Journal of Hydraulic Engineering, 1987, ASCE 113(12), pp. 1510 - 1524

[7] Chen C.J., Laboratory verification of a dam - break flood model Journal of Hydraulic Division ASCE, 106(4), 1980, pp. 535 - 556

[8] Chen C.L. Bingham plastic or Bagnold dilatant model as a rheological model of debris flow? Proc. of Third Int. Sympos. on river sedimentation, University of Mississippi, 31st March - 4th April 1986

[9] Chen L.C., Generalized visco-plastic modelling of debris flow Journal of Hydraulic Engineering, 1988, 114, pp. 237 - 258

[10] Chen C.L., Ling C.H., Resistance formulas in hydraulics based models for routing debris flow in Debris Flow Hazard Mitigation: Mechanics, Prediction and Assessment, Eds. Chen, New York, 1997, pp. 360 - 372

[11] Courant R., Friedrichs K.O., Supersonic flow and shock wave Interscience Publisher Inc., New York, 1948

[12] Coussot P. Steady, laminar, flow of concentrated mud suspensions in open channel, Journal of Hydraulic Research, Vol. 32, n. 4, pp.535-559, 1994

[13] Deangeli C., The Role of Slope Geometry on Flowslide Occurrence, American Jou. of Environmental Sciences, Scipub, New York, 3 (3), 2007, pp. $93-97$

[14] Deangeli C., Laboratory Granular Flows generated by Slope Failures, Rock Mechanics Rock Engineering, Springer, Netherlands, 41 (1) 2008, pp. 199 217

[15] Dent J.D., Lang T.E., A biviscous modified Binghman model of snow avalanche motion Annals of Glaciology, 4, 1983, pp. $42-46$

[16] De Wrachien D. Debris and hyper-concentrated flows, in G. Lorenzini, C.A. Brebbia, D.E. Emmanouloudis (eds) Monitoring, Simulation, Prevention and Remediation of Dense and Debris Flow, Rhodes, Greece, 2006

[17] De Wrachien D., Mambretti S. Dam-break shock waves: A two-phase model for mature and immature debris flow Second International Conference on Debris Flow, 18 - 20 June 2008, The New Forest, United Kingdom

[18] De Wrachien D., Mambretti S. Dam break with floating debris: a 1D, twophase model for mature and immature flow propagation International 
14 Monitoring, Simulation, Prevention and Remediation of Dense and Debris Flows III

Conference on Agricultural Engineering and Industry Exhibition, 23 - 25 June 2008, Hersonissos, Crete, Greece

[19] Dressler R.F. Hydraulic resistance effect upon the dam-break functions Proc. of Royal Society of London A(257), 1952, pp. 185 - 198

[20] Eckersley J.D., Instrumented laboratory flowslides, Geotechnique, 40, N. 3, 1990, 489-502.

[21] Fink J.H., Malin M.C., D’Alli R.E., Greeley R. Rheological properties of mudflows associated with the spring 1980 eruptions of Mount St. Helens volcano, Washington Geophys. Res. Lett., 8, 43-46, 1981.

[22] FLAC manuals, 2001, Version 4, ITASCA Consulting group, Minneapolis, USA

[23] Fread D. L., Jin M., One-dimensional Routing of Mud/Debris flows using NWS FLDWAV Model, in Proc. of First International Conference on Debris Flow Hazards Mitigation: Mechanics, Prediction and Assessment, San Francisco, California, 7-9 August 1997

[24] Ghilardi P., Natale L., Savi F., Debris flow propagation and deposition on urbanized alluvial fans, Excerpta, 14, 2000, pp. 7 - 20

[25] Hanes D.M. Studies on the mechanics of rapidly flowing granular-fluid materials, Thesis presented to Univ. of California at San Diego, Calif., 1983

[26] Harten A. High resolution schemes for hyperbolic conservation laws Journal of Computational Physics, 49, 1983, pp. 357-394

[27] Hirano M., Hasada T., Banihabib M.E., Kawahasa K., Estimation of hazard area due to debris flow in Debris Flow Hazard Mitigation: Mechanics, Prediction and Assessment, Eds. Chen, New York, 1997, pp. 697-706

[28] Honda N., Egashira S., Prediction of debris flow characteristics in mountain torrents in Debris Flow Hazard Mitigation: Mechanics, Prediction and Assessment, Eds. Chen, New York, 1997, pp. 707-716

[29] Hunt B., Asymptotic solution for dam-break problems Journal of Hydraulic Division ASCE, 108(1), 1982, pp. 115-126

[30] Ishihara, K., Tsukamoto Y., Shibayama T., Evaluation of slope stability against flow in saturated sand. Reports on Geotechnical engineering, Soil mechanics and Rock engineering, Jubilee volume of Terzaghi Brandl 2000. Wien, 2000-2001, Vol. 5, Institut fur Grundbau und BodenmechanikTechnische Universitat Wien Ed., 2003, pp. 41-54.

[31] Jan C.D., A study on the numerical modelling of debris flow in Debris Flow Hazard Mitigation: Mechanics, Prediction and Assessment, Eds. Chen, New York, 1997, pp. 717-726

[32] Johnson A.M. Physical processes in geology Freeman Ed., San Francisco, 1970

[33] Julien P.Y., O’Brien J.S., Physical properties and mechanics of hyperconcentrated sediment flows in Proceeding Spec. Conference on Delineation of Landslides, Flash Flood and Debris Flow Utah, USA, 1985, pp. 260-279

[34] Lade P. Static instability and liquefaction of loose fine sandy slopes $J$. Geotech. Engng Div ASCE 118, 1, 1992, 51-71. 
[35] Lax P., Wendroff B., Systems of conservation laws Comp. on Pure and Applied Mathematics 13, 1960, pp. 217-237

[36] Lee J., Cowin S.C., Templeton III J.S. An experimental study of the kinematics of flow through hoppers. Trans. Soc. Rit., 18, 247-269, 1974.

[37] Lorenzini G., Mazza N. Debris flow. Phenomenology and Rheological Modelling WIT Press, Ashurst Lodge, Southampton, UK, 2004

[38] Mambretti S., Larcan E., De Wrachien D. 1D modelling of dam - break surges with floating debris Biosystems Engineering, Vol. 100(2), June 2008, pp. 297-308

[39] McCormack R.W., The effect of viscosity in hypervelocity impact cratering AIAA Paper, 1969, 75-1

[40] Norem H., Locat J., Schieldrop B., An approach to the physics and the modelling of the submarine flowslides Marine Geotechnical 9, 1990, pp. 93-111

[41] O'Brien J.S., Julien P.J., Fullerton W.T., Two-dimensional water flow and mudflow simulation, Jou. of Hydraulic Engineering, 1993, 119, pp. 244261

[42] Okuda S., Suwa H., Okunishi K., Yokoyama K., Nakano M. Observations on the motion of a debris flow and its geomorphological effects, $J$. Geomorphol., suppl. 35, 142-163, 1980

[43] Picarelli L., Olivares L., Comegna L., Damiano E. Mechanical Aspects of Flow-Like Movements in Granular and Fine Grained Soils, Rock mechanics rock engineering Springer, Netherlands, 41 (1) 2008, pp. 179-197.

[44] Poulos S.J., The steady state of deformation. Jou. of Geotechnical Eng. Div., ASCE, 107, 1981, pp. 553-561

[45] Poulos S.J., Castro G., France J.W., Liquefaction evaluation procedure, Jou. Geotechnical. Eng. Div. ASCE, 111(6), 1985, pp. 772-792.

[46] Ritter A. Die Fortplanzung der Wasserwellen Zeitschrift des Vereines Deutscher Ingenieure 36(3), 1892, pp. 947 - 954 (in German)

[47] Sakkas J.G., Strelkoff T. Dam break flood in a prismatic dry channel $J$. Hyd. Div. ASCE 99(12) 2195-2216, 1973

[48] Sivathayalan, S., Vaid, Y. P. (2002): Influence of generalized initial state and principal stress rotation on the undrained response of sands. Can. Geotech. Jou., 39, 63-76.

[49] Sladen J.A., d'Hollander R.D., Krahm J., The liquefaction of sands, a collapse surface approach, Can Geotech Jou., 22, 1985, pp. 564-578.

[50] Stoker J.J. The breaking of waves in shallow water Annuals New York Academy of Science 51(3), 1949, pp.360-375

[51] Spence K.J., Guymer I., Small scale laboratory flowslides, Geotechnique, 47, 5, 1997, pp. 915-932.

[52] Strelkoff T., Falvey H.T. Numerical methods used to model unsteady canal flow J. Irrig. and Drain. Engrg, ASCE, 119(4), 637-655, 1993

[53] Takahashi T. Debris flow Rev. Fluid Mechanics, 13, pp. 57-77, 1981

[54] Takahashi T. Debris Flow, 165 pp., A. A. Balkema, Brookfîeld. Vt. 1991.

[55] Takahashi T, Initiation of flow of various types of debris flow Proceeding Second International Conference on Debris Flow Hazard Mitigation: 
16 Monitoring, Simulation, Prevention and Remediation of Dense and Debris Flows III

Mechanics, Prediction and Assessment, Eds. Wieczorak and Naeser, Rotterdam, 2000, pp. 15-25

[56] Takahashi T., Nakagawa H., Flood / debris flow hydrograph due to collapse of a natural dam by overtopping Journal of Hydroscience and Hydraulic Engineering, 1994, 12, pp. 41-49

[57] Van Leer B., Towards the ultimate conservative difference scheme Journal of Computational Physics 23, 1977, pp. 263-275

[58] Wan Z. Hyperconcentrated flow Monograph Series of IAHR, Rotterdam, 290 pp., 1994 